\title{
METHOD DEVELOPMENT AND SURFACE UTILIZATION: MONITORING ENVIRONMENT IN URBAN SOCIETY THROUGH ANALYTICAL CHEMISTRY
}

\author{
Surjani WONORAHARDJO
}

DOI: 10.21163/GT_2019. 141.22

\begin{abstract}
:
Environmental changes following urban area development must be considered. Analytical chemistry deals with methods to analyze environment and all impacts of changes in chemistry level. Probes to label problems in environmental level, such as presence of hazards, changes of crops behavior, loss of certain biodiversity, can be the key information. Method development and new friendly materials creation, are proposed to answer the challenge. Some new materials, like catalytic converter and gas reduction agents will find their significance. Moreover, the frame of green chemistry would lead one to better achievement dealing with natural law. Surface utilization and separation techniques are important concepts in application of material for analysis and probe designing, which are based on surface equilibrium. The aim of this paper is to summarize key concepts in materials' surface and the role of analytical chemistry methods in anticipating environmental problems including those that arise from the urban society development, based on chemistry findings reported. Some method development as well as materials design examples are also presented.
\end{abstract}

Key-words: Analytical Chemistry, Environment in Urban Society, Green Chemistry, Method Development of Analysis, Surface Utilization.

\section{INTRODUCTION}

Human society faces a great deal of environmental challenges regarding the changing of nature due to modern activities. A large number of urban areas around the world is now growing continuously. Methods of environmental urban design and analysis are then considered seriously especially in high density area (Chan \& Lee, 2009). Climate changing, pollutions, loosing of biodiversity are some example of problems from the activities in urban society (Azapagic et al., 2007; Preston, 2015). Moreover, some environmental "disasters" are also noted in history, such as Minamata tragedy, acid rain, Bhopal and Chernobyl accident, Donnana mining catastrophe (Ali \& Khan, 2016), which are all directly or indirectly related to the growing urban activities. Prevention and mitigation of environmental problems demand science as the important part of the actions (Ali \& Khan, 2016; Kayasth \& Swain, 2004). Analysis in chemistry level can be reflected as the key role to open the interdisciplinary discussion about nature, ecosystem and environment. While the chemistry explanations can be performed at a laboratory level, then at a bigger scale, the ecosystem and environment with all additional complexity, can be studied by the aid of related disciplines. Analytical chemistry provides qualitative and quantitative methods as well as the future proposal to deal with consequences of using full scale method (Bhatnagar \& Minocha, 2006). Chemistry procedures are in an increased attention since the green perspective encourages new concepts and safer processes (Stoll, 2011; Glaser, 2008).

\footnotetext{
${ }^{1}$ State University of Malang, Faculty of Mathematics and Science, Chemistry Department, Jl. Semarang 5, 65145 Malang, Indonesia, surjani.wonorahardjo@um.ac.id
} 
Green chemistry has twelve principles as a framework in any process including designing and improving materials, products, and processes. There are also some ways of evaluation of the "health" of our environment. One well known example is called life cycle assessment (LCA) (Tufvesson et al., 2013) as a technique to describe the surroundings. Pollution is also described as side effect of living activities to the nature, and this can be one important probe to inform the condition of environment, as a whole. Some elemental analysis can also be used as a good probe to enable risk management system (Ali \& Khan, 2016; Wijaya et al., 2012). In this case, green chemistry is discussed everywhere in the world and becomes important in the future including the urban design environment, including in urban society, in which more materials are created and integrated to the scheme of maintaining the natural balance..

In this paper, chemistry changes related urban society development is discussed in analytical method developments depending on each problem. Materials for environment is one approach for defending natural equilibrium, and surface exploitation plays a greater role. The discussion is summed up by acclaiming the role of analytical chemistry as well as the need to put chemistry education for future wholistic environmental awareness in younger society.

\section{ENVIRONMENTAL CHEMISTRY - URBAN CHEMISTRY}

Environment constantly interact with living things and change in response to the conditions of their environment. As a complex system of matter, can be seen in details from the perspective of chemistry state and processes, before further analysis can be performed. Environmental chemistry is usually defined as scientific study of chemical (and biochemical) phenomena occurring in nature. The equilibrium in environment is maintained by certain natural processes and this condition is perfect, so that the changes in equilibrium will result in adaptation to reach new state of equilibrium.

Planning in urban areas comprises some assessment for the environment including physical and chemical and other natural process. This living area must be naturally clean and healthy for all, while everyday life and human activities can also give imbalance to the nature in the surrounding (Azapagic et al., 2007; Kampa \& Castanas, 2008; Elom et al., 2014; Sitaras \& Siskos, 2008). There are constant changes in the surroundings introduced by the interaction of the living species with the nature, as all make some ways of evolutionary "adaptation" to new circumstance. Other inherent abiotic aspects from nature including sunlight, wind, soil, water, climate form a complex self-reorganization behavior in presence of society. This might also include the danger of environmental pollution arising from human and more industrial activities (Espíndola-Gonzalez et al., 2010; Shukla et al., 2012; Wang et al., 2006; Srogi, 2007). Computer modelling on specific data also shapes the future of urban design (Jeon et al., 2008).

\section{METHODS DEVELOPMENT IN ANALYTICAL CHEMISTRY FOR URBAN ENVIRONMENT}

In this era, analytical chemists have been in the forefront of most influencing applications (Wise et al., 2006). Chemistry level up to the environmental scale chemistry uses some indicators from the nature to overcome uneasy changes. In this case, method development is the way analytical chemistry contributes, and analytical steps will find its way (Azapagic et al., 2007). Indicators can be of goodness or wellness of the system or of 
possible damaged of the healthy cycles in environment. Due to complexity of the origin of problems, analytical assessment (Azapagic et al., 2007; Ali \& Khan, 2016; Tobiszewski et al., 2009; Zolotov, 2010; Gałuszka et al., 2013) is needed to be applied wisely and strictly considered in developing urban design.

The first attempt in analytical assessment process must be the decision on monitoring indicators. When problems arise, the imbalanced nature would provide some clue to analyze. Water and soil contain so many chemistry parameters to describe the health of ecosystems, the presence of some pollutant chemicals provide also a way to describe the environment quality. From those indicators, analytical methods can be developed and validated. Some statistical analysis is also usually needed to extract important data from the collections and endorse the hypothesis. The separation is considered to guarantee the results, which can be crucial with all consequences. Analysis can be performed qualitatively to describe profiles, or quantitatively to get the real concentration in certain units.

Indicators at a chemistry level can be assessed from the root of the problems. Human activities in urban society generate waste products, which flow into the water, are released to the air, or can be buried and consequently contaminate the soil. Waste products can be from household activities, in form of biodegradable materials as well as non-biodegradable rubbish like plastics and metals. Toxic gasses from vehicles as well as the carbon dioxide released from urban activities are also indicators for the health of the environment. Heavy metal, in this case lead $(\mathrm{Pb})$ from the processed fossil fuel, is a common problem in urban society, while using biofuels would end up in global warming as more carbon dioxide is released into the atmosphere. When industrial activities are present, more possible toxic waste would automatically need special treatment before released to environment. There are standard methods for environmental monitoring including urban areas. However, there are some specific methods necessary to solve new problems arising from specific activities. Table 1 consist of some examples of methods development in urban environment which depend on the probe indicators.

Not to be overlooked, green analytical practices must accompany modern activities in urban society, especially in dealing with emerging industries. Analytical methods are available to examine chemicals in wide variability. Every method has advantages and drawbacks depending on the aims and perspectives. However, there is no single perfect methods that can be considered green enough to be the standard treatment on every sample (Gałuszka et al., 2013). There are special considerations on solvents used for analysis as well as on the waste. Besides, sampling techniques and instrumentation chosen usually depends on the sample and availability of the instrument. Small scale experiments are always encouraged and the chemometrics principle can be applied to data analysis.

More to analytical processes, there are also several parameters involved in the choosing methods for bringing the best alternative. Representativeness, accuracy, precision, selectivity, sensitivity and detectability are amongst the parameters for instrumentations too. However, in the green chemistry point of view, non-invasive, safer and close to zero waste processes are preferable (Gałuszka et al., 2013). Impact for the environment is also one strong reason to think through in adjusting the risk management before one intended process is carried out.

There are lots of chemistry works reported in the scheme of environmental monitoring, due to human activities. There were more reports on each particular problem relating to the environment of the urban area. One type of pollution can be traced back to the metal contamination in soils, heavy metal and magnetic properties of topsoil (Wang et al., 2013). 
The investigations on airborne and air quality due to heavy metals pollution were also considered (Wijaya et al., 2012; Sitaras \& Siskos, 2008; Chung et al., 2006; Liu et al., 2011; Chung et al., 2008). Other type of investigations refer to the wet environment, including sewage and waste water and river sediments (Wijaya et al., 2012).

Table 1. Examples of method Development of urban-environment.

\begin{tabular}{|c|c|c|c|}
\hline Probe Indicators & $\begin{array}{c}\begin{array}{c}\text { Type of Phenomenon } \\
\text { observed }\end{array} \\
\end{array}$ & $\begin{array}{c}\text { Specific Method } \\
\text { Development }\end{array}$ & Refs. \\
\hline Heavy metals and $\mathrm{Pb}$ & $\begin{array}{l}\text { Higher metal content in } \\
\text { river sediment and road- } \\
\text { dust }\end{array}$ & $\begin{array}{l}\text { Inductively Coupled Plasma- } \\
\text { Mass Spectrometry (ICP MS) }\end{array}$ & Wijaya et al. (2012) \\
\hline $\begin{array}{l}\text { Heavy metals } \\
\text { distribution }\end{array}$ & $\begin{array}{l}\text { Air quality in } \\
\text { industrialization area }\end{array}$ & Computer-model development & Jeon et al. (2008) \\
\hline \begin{tabular}{|l|} 
Elements for \\
biomonitoring
\end{tabular} & Dry moss & Elemental analysis & $\begin{array}{l}\text { Lee et al. (2004), } \\
\text { Aničić et al. (2009) }\end{array}$ \\
\hline $\begin{array}{l}\text { Heavy metals and } \\
\text { magnetic properties } \\
\text { of topsoil }\end{array}$ & $\begin{array}{l}\text { Emission of harmful } \\
\text { magnetic minerals } \\
\text { adsorbed on soil }\end{array}$ & $\begin{array}{l}\text { Magnetic field measurement } \\
\text { and data analysis }\end{array}$ & Wang et al. (2013) \\
\hline $\begin{array}{l}\text { Heavy metals, } \\
\text { organic toxic, } \\
\text { particulate matter }\end{array}$ & $\begin{array}{l}\text { Human health } \\
\text { disturbance }\end{array}$ & $\begin{array}{l}\text { Biological examinations in } \\
\text { respiratory, urinary, digestive } \\
\text { systems }\end{array}$ & $\begin{array}{l}\text { Kampa \& Castanas } \\
(2008)\end{array}$ \\
\hline $\mathrm{Pb}$ metal & Human health & $\begin{array}{l}\text { Oral Bio-assessability: Atomic } \\
\text { spectroscopy }\end{array}$ & Elom et al. (2014) \\
\hline Heat island (HI) & Non comfort area & $\begin{array}{l}\text { Assessing adaptive thermal } \\
\text { comfort }\end{array}$ & Rijal (2016) \\
\hline $\mathrm{CO}_{2}$ captured & $\mathrm{CO}_{2}$ emission & Data analysis & $\begin{array}{l}\text { Roldán-Fontana, et } \\
\text { al. (2017) }\end{array}$ \\
\hline $\begin{array}{l}\text { Polycyclic aromatic } \\
\text { hydrocarbon (PHA) }\end{array}$ & PHA content on Lichens & $\begin{array}{l}\text { Extraction method (soxhlet) } \\
\text { followed by HPLC }\end{array}$ & $\begin{array}{l}\text { Shukla et al. (2012), } \\
\text { Srogi (2007) }\end{array}$ \\
\hline
\end{tabular}

There is also a tendency to entangle the discussion in chemistry and biology or at a microbiology level. Biological indicators are also important to be followed. One good example is the use of Lichens to monitor industrial activities which emit toxic Polycyclic Aromatic Hydrocarbons (Srogi, 2007), from essential elements for bio-monitoring of soil and crops (Lee et al., 2004; Aničić et al., 2009; Wang et al., 2012). More than chemistry, there are many biomarkers (Sures et al., 2014) able to probe the conditions of an ecosystem and of the environment, similar to lichens as polycyclic aromatic hydrocarbons marker. The living organism gives specific response modulated by internal and external parameters. This type of condition can be also tracked down by biochemistry methods.

The challenge of probing new toxic contaminants, with lower concentration, has nowadays been in the first row attempts. Good detection limit is one of the key concepts which defend human health in the long run. The discussion about analytical advanced techniques for environment monitoring also describes the complexity of environmental problems, including those which originated from urban activity. Analytical chemistry plays an important role in giving methods to assess chemicals presence, correlate them with the situation and offer future solution. The probe of analysis can be anything of many choices possible in the environment that is related to the urban society activities. It can be the quality monitoring of air, water, as well as soil in the surroundings. 
Much analytical chemistry data in fact do not stand alone in the analysis. Collaborative strategy between sciences would yield better knowledge on how to generate urban environment analysis (Ali \& Khan, 2016). More sets of data give different information from different angles for the same problems. Computer model development based on analytical chemistry data was also proposed (Jeon et al., 2008) in industrialization area. This is an example of extracting data available from any methods, to acquire meaningful analysis. In the future, some more prediction can be drawn based on data and models, to assess the condition of urban area. There was also one study reported on analyzing the carbon dioxide capture to address the stages of urban environment development via the energy consumption (Roldán-Fontana et al., 2017). Beside the computer modelling, the use of modern instrumentation is also demanding to give specific information from a different point of view. The information gained from the nuclear magnetic resonance (NMR) relaxation of proton nuclei absorbed in cement porous media was reported (Ardelean, 2019; Bede, et al., 2016). Such information is useful in designing of new types of cement- based materials, with lower ecological fingerprint, to be used for urban society development.

The other way to maintain environmental balance, which ideas emerge continuously during modern time, is by creating new devices to deal with the chemicals which generate problems. This is also a great future for material science so far, to meet the wider area of applications. Based on various method development in urban-environment problems discussed above, the need of new materials is unavoidable. More comprehension leads to more attempts to overcome problems as early as possible. This way new materials for environment are created.

\section{MATERIALS FOR ENVIRONMENT}

Besides the analytical chemistry for environment, which rely on method developments, the other booming matter in science is material chemistry for environment (Ali \& Khan, 2016). The materials for environment are commonly porous media and this needs applied chemistry for surface producing. The material has high surface area and can be good in adsorbing gasses or other targeted molecules. Since environmental problems are usually related to toxic gasses and pollutants, toxic chemicals and waste products in water, most materials are designed to reduce or to moderate the amount of unfriendly chemicals. However, there are many other purposes of material inventions for modern life, such as materials used to fulfill comfort zones in urban area (Rijal, 2016). Comfortable style in $20^{\text {th }}$ century is now important and bring also its attributes.

Table 2. Some Examples of Material Created for Urban-Environment.

\begin{tabular}{|c|c|c|c|c|}
\hline Materials & Functions & $\begin{array}{c}\text { Method of material } \\
\text { development }\end{array}$ & Principles & \multicolumn{1}{|c|}{ Refs. } \\
\hline $\begin{array}{c}\text { Phase Changes } \\
\text { Materials (PCM) }\end{array}$ & $\begin{array}{c}\text { Air cooling in } \\
\text { buildings }\end{array}$ & $\begin{array}{c}\text { Developing packed } \\
\text { units of PCM }\end{array}$ & $\begin{array}{c}\text { Energy adsorbed and } \\
\text { desorbed }\end{array}$ & Silalahi et al. (2016) \\
\hline $\begin{array}{c}\text { Cellulose with } \\
\text { modified surface }\end{array}$ & $\begin{array}{c}\text { Reducing } \mathrm{CO}_{2} \\
\text { and } \mathrm{SO}_{x} \text { gasses }\end{array}$ & $\begin{array}{c}\text { Shredded coconut } \\
\text { packed in column }\end{array}$ & Interface adsorption & $\begin{array}{l}\text { Wonorahardjo, et al. } \\
(2016)\end{array}$ \\
\hline $\begin{array}{c}\text { Amine supported } \\
\text { sorbent }\end{array}$ & Adsorb $\mathrm{CO}_{2}$ & $\begin{array}{c}\text { Modification of } \\
\text { sorbent surface }\end{array}$ & $\begin{array}{c}\text { Cycle of } \mathrm{CO}_{2} \text { in } \\
\text { atmosphere for algae } \\
\text { cultivation }\end{array}$ & $\begin{array}{l}\text { Brilman, et al. } \\
(2013)\end{array}$ \\
\hline Carbon & Capture of $\mathrm{CO}_{2}$ & Amine modification & $\begin{array}{c}\text { Surface modification, } \\
\text { interface adsorption }\end{array}$ & Chen et al. (2013) \\
\hline
\end{tabular}


In Table 2 some examples of materials for urban environment are presented, together with the functions and principles.

Important materials in urban area are related to buildings and infrastructure. Concrete and wood, cements, steels are also analyzed and monitored. Building mass and configuration give impacts in comfort zone and environment (Roldán-Fontana et al., 2017; Wonorahardjo, 2012). In turn there are also changes in soil, water, and air in the surroundings. On the other hand, new materials were invented to recover natural balance as a whole systems (Sures et al., 2014).

Nano-sized materials are preferable dealing with chemistry in the environment (Xue et al., 2016) such as in water monitoring and remediation for better environment, or materials for reducing pollutants (Xue et al., 2016) catalytic converters (Isaksen et al., 2009) materials which are environmentalfriendly. Some biomaterials from coconut cellulose were also made for reduction of unfriendly gasses (Wonorahardjo et al., 2016). Similar to this, an attempt to capture carbon dioxide was done for microalgae cultivation (Brilman et al., 2013). Having the adsorptive properties on carbon, there is also an enrichment of the carbon surface to capture carbon dioxide (Houshmand et al., 2012; Yu et al., 2012). Reaching nano-dimension is important in relation with high surface area needed. Nanomaterials development can be controlled from the beginning of the formation, basically via sol-gel processes, with physical treatments everywhere. Indeed, in this case chemistry is the science of transformation of a substance at chemistry level, as discussed in chemistry philosophy (Brakel, 1997), allowing experts to do experiments in accordance to desirable properties and solving problem purposes.

Other type of materials rely on utilization of waste products from human activities. Agro-waste materials are usually beneficial, having enough properties to be used further, and also still environmental friendly. Cellulose is among waste materials used for environment purposes, as gas reduction agents (Wonorahardjo et al., 2016) or water remediation agent(Yu et al., 2012; Brakel, 1997). Carbon and silica are widely used for many other similar purposes. There is also one important aim in developing materials for environment, which is related to energy (Bon \& Ferrara, 2007). The future of renewable energy must be approached also through material chemistry, in form of making replacement of fossil fuels, or in form of exploitation of solar energy by developing more powerful solar panels (Kiesgen et al., 2013).

Related to housing in urban area, some materials are created to regulate thermal comfort in housing planning. This is also one type of mitigation action of urban heat island, which is important nowadays (Wonorahardjo, 2012). For this action several materials can regulate the flow of heat in between buildings in urban area (Silalahi et al., 2016). Thermophysical parameters of phase changing materials (PCM) from coconut oil (Silalahi et al., 2016) is used to regulate the thermal comfort zone.

The freezing and melting properties of coconut oil (mostly consist of lauric acid) was used to produce temperature difference due to the exchange energy between phases. On the other hand, silica-cellulose hybrid material can be one environmental friendly alternatives (Feng et al., 2016) to manage thermal and acoustic applications. Choosing raw material for concrete is also an interesting topic in housing in urban society. Modifying the concrete properties by silica from agro-waste have been reported (De Souza et al., 2000; Sakr \& Ash, 2006). More material modification was reported to regulate thermal comfort in house planning (Feng et al., 2016). 
There are also some analytical parameters needed to make clear such as detection limit, sensitivity, selectivity, to describe the analytical methods or products. The challenge expands creativity to make better materials with good analytical parameters, higher sensitivity, smaller detection limit, and also zero waste for the forces itself. Desirable physical properties usually include useful physical characteristics such as optical and magnetic properties, chemical characteristic such as catalytic properties. Biomaterials are also come into challenging impacts since they are usually biodegradable in the process and result. However, the other challenge of biomaterials is related to reproducibility and effectivity of the product materials. The modern analytical techniques result in small, practical, and green devices which are good in term of analytical parameters and sustainability (Crawford et al., 2017).

\section{SURFACE UTILIZATION}

Most of designed materials are based on surfaces of porous media. Adsorption and surface equilibrium can be the key concepts to develop new beneficial processes. Polarity of the surface is subject for modifications and become the driving force for the device performance. We can improve the surface (Sakr \& Ash, 2006) during the sol-gel processing (Wonorahardjo et al., 2000). Pore size distribution and active functional groups can be the key role for application. Modifications on surfaces, integration with other types of material can alter the surface properties too (Wonorahardjo et al., 2016).

Most of conventional adsorbents of pollutants also used surface modifications (Bhatnagar \& Minocha, 2006). The silanols (Si-OH) on large surface area can be good absorbent for organic toxic and unfriendly molecules, retain them in the tortuosity of the pore system. Well known surface properties would yield in better capacity of utilization for any purpose, including the need of material for urban designs.

The concepts of surface dynamics was previously done by the aid of NMR relaxation and diffusion techniques. Some case studies in partially filled porous silica glasses were performed using NMR relaxation and diffusion techniques (Mattea et al., 2004). Analysis of cement materials was also done by NMR relaxometry techniques giving thorough understanding of the water behavior inside the pores (Bede et al., 2016). In the future, material's interface becomes important for many purposes. For example, separation of gasses by sorption extraction has been developed since the interface properties were examined (Ali \& Khan, 2016; Xue et al., 2016).

\section{ROLE OF ANALYTICAL CHEMISTRY}

In this modern era, chemistry as natural science suggests a complementary discourse which is more wholistic in view. The role of chemistry has to be emphazised and included in cultural activities with broader context (Sjöström et al., 2007). Since chemistry can be the key method for environmental analysis, the discussion can be influencial in broader audience. In education, the topics can be delivered interdiciplinary. The idea is to make chemistry contributes progress and improvements for modern society. 
Since the chemistry dicipline is actually pragmatic and based on empirism, more mutual collaboration with this science would be valuable in developing urban society. Probing material must be found and analyzed before further method development.

As previously mentioned, education is important in forming disciplinary discourses. Therefore, a discussion of the discourse of chemistry must include chemistry education, both as a research area to take examples from and as a practice to change when striving beyond the current mainstream discourse of chemistry.

Some processes in molecular level such as gelling process (Wonorahardjo et al., 2000), freezing-melting process (Silalahi et al., 2016) dynamics in the interface (Mattea et al., 2004) would involve energy changes to the environment. These are only example in smaller scale of environment that can be the key concept in understanding the changes in environment. These chemical concepts are important too in preparing urban society planning, and must become integrated in the urban planning curriculum.

Chemistry education is also reflective to environment (Sjöström et al., 2016) in which the role is significant.

\section{CONCLUSION}

The key concept in environmental analysis can be traced through analytical chemistry methods. The changing in global scope as well as the damaged of small scale environment can be investigated in the chemistry laboratories via some conditioned probes. Some synthesized materials, especially those with special surface properties can also be the alternatives in solving environmental harms. Method developments as well as materials design become essential from time to time. Moreover, environmental awareness in urban society must be integrated in school curricula as well as in chemistry education outcomes. Future research would deal with sophistication on materials for environment as well as automatisation or computer programmed environmental sensors.

\section{REFERENCES}

Ali, H. \& Khan, E. (2016) Environmental Chemistry in the Twenty-First Century. Environmental Chemistry Letters, 15(2), 1-18.

Aničić, M., Tasić, M., Frontasyeva, M. V., Tomašević, M., Rajšić, S., Strelkova, L. P., Popović, A. \& Steinnes, E. (2009) Active Biomonitoring with Wet and Dry Moss: A Case Study in an Urban Area. Environmental Chemistry Letters, 7(1), 55-60.

Azapagic, A. Pettit, C. \& Sinclair, P. (2007) A Life Cycle Methodology for Mapping the Flows of Pollutants in the Urban Environment. Clean Technologies and Environmental Policy, 9(3), 199214.

Bede, A., Scurtu, A. \& Ardelean, I. (2016) NMR relaxation of molecules confined inside the cement paste pores under partially saturated conditions. Cement and Concrete Research, 89, 56-62.

Bhatnagar, A. \& Minocha, A. K. (2006) Conventional and Non-Conventional Adsorbents for Removal of Pollutants from Water-A Review. Indian Journal of Chemical Technology, 13(3), 203-217.

Bon E. P. S. \& Ferrara, M. A. (2007) Bioethanol Production via Enzymatic Hydrolysis of Cellulosic Biomass. The Role of Agricultural Biotechnologies for Production of Bioenergy in Developing Countries, FAO Seminar 12 October 2007, 1-11 
Brilman, W., Alba, L. G. \& Veneman, R. (2013) Capturing Atmospheric $\mathrm{CO}_{2}$ Using Supported Amine Sorbents for Microalgae Cultivation. Biomass and Bioenergy, 53, 39-47.

Chan E. H. W. \& Lee, G. K. L. (2009) Design Considerations for Environmental Sustainability in High Density Development: A Case Study of Hong Kong. Environment, Development and Sustainability, 11(2), 359-374.

Chung, Y., Kim, S., Moon, J., Kim, Y., Lim, J. \& Lee, J. (2006) Source Identification and Long-Term Monitoring of Airborne Particulate Matter (PM 2.5/PM 10) In An Urban Region Of Korea. Journal of Radioanalytical and Nuclear Chemistry, 267(1), 35-48.

Chung, Y.-S., Kim, S.-H., Moon, J.-H., Kim, H.-R., Lim, J.-M. \& Lee, J.-H. (2008) Air Pollution Monitoring of an Urban Dust in Daejeon City, Korea by Using Instrumental Neutron Activation Analysis. Journal of Radioanalytical and Nuclear Chemistry, 278(2), 441-447.

Crawford, S.E, Hartung T., Hollert, H., Mathes, B., van Ravenzwaay, B., Steger-Hartmann, T., Studer, C. \& Krug, H.F. (2017) Green Toxicology: a strategy for sustainable chemical and material development. Environmental Sciences Europe, 29(1), 16.

De Souza, M. F., Batista, P. S., Regiani, I., Liborio, J. B. L. \& De Souza, D. P. F. (2000) Rice HullDerived Silica: Applications in Portland Cement and Mullite Whiskers. Materials Research, 3(2), 25-30.

Elom, N. I., Entwistle, J. \& Dean, J. R. (2014) Human Health Risk from Pb in Urban Street Dust in Northern UK Cities. Environmental Chemistry Letters, 12(1), 209-218.

Espíndola-Gonzalez, A., Martínez-Hernández, A. L., Angeles-Chávez, C., Castaño, V. M., \& Velasco-Santos, C. (2010), Novel Crystalline Sio(2) Nanoparticles Via Annelids Bioprocessing of Agro-Industrial Wastes. Nanoscale Research Letters, 5(9), 1408-1417.

Feng, J., Le, D., Nguyen, S. T., Nien, V. T. C., Jewell, D. \& Duong, H. M. (2016) Silica-Cellulose Hybrid Aerogels for Thermal and Acoustic Insulation Applications. Colloids and Surfaces A: Physicochemical and Engineering Aspects, 506, 298-305.

Gałuszka, A., Migaszewski, Z. \& Namieśnik, J. (2013) The 12 Principles of Green Analytical Chemistry and the SIGNIFICANCE Mnemonic of Green Analytical Practices. TrAC Trends in Analytical Chemistry, 50, 78-84.

Glaser, J. A. (2008) Green Chemistry and Technology. Clean Technologies and Environmental Policy, 10, 7-9.

Houshmand, A. H., Daud, W. M. A. W., Lee, M. \& Shafeeyan M. S. (2012) Carbon Dioxide Capture with Amine-Grafted Activated Carbon. Water, Air, and Soil Pollution, 223(2), 827-835.

Isaksen, I. S. A., Granier, C., Myhre, G., Berntsen, T. K., Dalsøren, S. B., Gauss, M., Klimont, Z., Benestad, R., Bousquet, P., Collins, W. (2009) Atmospheric Composition Change: ClimateChemistry Interactions. Atmospheric Environment, 43(33), 5138-5192.

Jeon, W., Shin, C. B., Kim, J. H., Kwak, B. K., Yi, J., Lee, J. H., Lee,W.G., Lee, S.W. \& Park, H. S. (2008) Analysis of the Distribution of Lead Concentration Under Steady State Conditions in Urban Multimedia Environment. Korean Journal of Chemical Engineering, 25(6), 1401-1406.

Kampa, M. \& Castanas, E. (2008) Human Health Effects of Air Pollution. Environmental Pollution, $151(2), 362-367$.

Kayasth, S. \& Swain, K. (2004) Role of Analytical Chemistry in Environmental Monitoring. Journal of Radioanalytical and Nuclear Chemistry, 262(1), 35-42.

Kiesgen, R., Richter, D., Ming, T. \& Caillol, S. (2013) Fighting Global Warming by Photocatalytic Reduction $\mathrm{Of}_{\mathrm{CO}_{2}}$ Using Giant Photocatalytic Reactors. Renewable and Sustainable Energy Reviews, 19, 82-106.

Liu, J. L., Bai, G., Chen, J., Zhu, L. Z., Guo, W. Q. \& Shen, X. Y. (2011) Total Volatile Organic Compound Concentration and its Influencing Factors in Urban Indoor Air after Decoration. Chinese Science Bulletin, 56(25), 2683-2689.

Lee, K. Y., Yang, M. K., Yoon, Y. Y., Shim, S. K., Cho, S. Y. \& Seo, B. K. (2004) Biomonitoring of Environmental Pollution Based on Studies of Trace Elements in Soil and Crops. Journal of Radioanalytical and Nuclear Chemistry, 259(1), 69-74. 
Mattea, C., Kimmich, R., Ardelean, I., Wonorahardjo, S. \& Farrher, G. (2004) Molecular Exchange Dynamics in Partially Filled Microscale and Nanoscale Pores of Silica Glasses Studied by Field-Cycling Nuclear Magnetic Resonance Relaxometry. Journal of Chemical Physics, 121(21), 10648-10656.

Preston, C. J. (2015) Framing an Ethics of Climate Management for the Anthropocene. Climatic Change, 130(3), 359-369.

Rijal, H. B. (2016) Field Study on Adaptive Thermal Comfort in Office Buildings in Malaysia, Indonesia, Singapore, and Japan During Hot and Humid Season. Building and Environment, 109, 208-223.

Roldán-Fontana, J., Pacheco-Torres, R., Jadraque-Gago, E. \& Ordóñez, J. (2017) Optimization of CO2 Emissions in the Design Phases of Urban Planning, Based on Geometric Characteristics: A Case Study of a Low-Density Urban Area in Spain. Sustainability Science, 12(1), 65-85.

Sakr, K., \& Ash, R. H. (2006) Effects of Silica Fume and Rice Husk Ash on the Properties of Heavy Weight Concrete. Journal of Materials in Civil Engineering, 18(3), 367-376.

Shukla, V., Patel, D. K., Upreti, D. K., \& Yunus, M. (2012) Lichens to Distinguish Urban from Industrial PAHs. Environmental Chemistry Letters, 10(2), 159-164.

Silalahi, A. O., Sukmawati, N., Sutjahja, I. M. \& Kurnia, D. (2016) Thermophysical Parameters of Organic PCM Coconut Oil from T-History Method and its Potential as Thermal Energy Storage in Indonesia. IOP Conference Series: Materials Science and Engineering, 214, 1-8.

Sitaras, I. E. \& Siskos, P. A. (2008) The Role of Primary and Secondary Air Pollutants in Atmospheric Pollution: Athens Urban Area as a Case Study. Environmental Chemistry Letters, 6(2), 59-69.

Sjöström, J., Eilks, I. \& Zuin, V. G. (2016) Towards Eco-Reflexive Science Education. Science and Education, 25(3-4), 321-341.

Srogi, K. (2007) Monitoring of Environmental Exposure to Polycyclic Aromatic Hydrocarbons: A Review. Environmental Chemistry Letters, 5(4), 169-195.

Stoll, M. L. (2011) Green Chemistry Meets Green Business: A Match Long Overdue. Journal of Business Ethics, 99(1), 23-28.

Sures, B., Ruchter, N., Zimmermann, S., Eisinger, M. \& Hollert, H. (2014) Progress in Ecotoxicology, Environmental Chemistry and Ecology. Environmental Sciences Europe, 26(1), 23.

Tobiszewski, M., Mechlińska, A., Zygmunt, B. \& Namieśnik, J. (2009) Green Analytical Chemistry in Sample Preparation for Determination of Trace Organic Pollutants. TrAC Trends in Analytical Chemistry, 28(8), 943-951.

Tufvesson, L. M., Tufvesson, P., Woodley, J. M. \& Borjesson, P. (2013) Life Cycle Assessment in Green Chemistry: Overview of Key Parameters and Methodological Concerns. The International Journal of Life Cycle Assessment, 18(2), 431-444.

van Brakel, J. (1997) Chemistry as the Science of the Transformations of Substances. Synthese, 111(3), 253-282.

Wang, B., Xia, D. S., Yu, Y., Jia, J. \& Xu, S. J. (2013) Magnetic Records of Heavy Metal Pollution in Urban Topsoil in Lanzhou, China. Chinese Science Bulletin, 58(3), 384-395.

Wang, J., Siegel, P. D., Lewis, D. M., Wallace, W. E., Ashley, K. \& Stettler, L. E. (2006) Spectroscopic Techniques in Industrial Hygiene. Encyclopedia of Analytical Chemistry: Applications, Theory and Instrumentation, 1, 1-42.

Wang, Z., Yang, P., Wang, Y. \& Ma, X. (2012) Urban Fractionation of Polycyclic Aromatic Hydrocarbons from Dalian Soils. Environmental Chemistry Letters, 10(2), 183-187.

Wijaya, A. R., Ouchi, A. K., Tanaka, K., Shinjo, R. \& Ohde, S. (2012) Metal Contents and Pb Isotopes in Road-Side Dust and Sediment of Japan. Journal of Geochemical Exploration, 118, 68-76.

Wise, S. A., Barcelo, D., Garrigues, P. \& Turle, R. (2006) Advances in Analytical Techniques for Environmental Analysis. Analytical and Bioanalytical Chemistry, 386(4), 765-767. 
Wonorahardjo, S. (2012) New Concepts in Districts Planning, Based on Heat Island Investigation. Procedia-Social and Behavioral Sciences., 36, 235-242.

Wonorahardjo, S., Ball, G. E., Hook, J. \& Moran, G. (2000) $2 H$ NMR Relaxation Monitoring of Gelation in Tetramethoxysilane Sol-Gels. Journal of Non-Crystalline Solids, 271(1-2), 137146.

Wonorahardjo, S., Ibnu, M. S. \& Budiasih, E. (2016) Sulfur Dioxide and Ammonia Gas Reduction Using Coconut Cellulose and Acetylated Cellulose. Chemistry and Chemical Engineering, Biotechnology, Food Industry, 17(2), 179-188.

Wonorahardjo, S., Wijaya, A. R. \& Suharti, S. (2016), Surface Behavior of Rhodamin and Tartrazine on Silica-Cellulose Sol-Gel Surfaces by Thin Layer Elution. The Journal of Pure and Applied Chemistry Research. 5(2), 48-54.

Xue, X., Cheng, R., Shi, L., Ma, Z., \& Zheng, X. (2016) Nanomaterials for Water Pollution Monitoring and Remediation. Environmental Chemistry Letters, 15(1), 23-27.

Yu, C. H., Huang, C. H., \& Tan, C. S. (2012) A Review of $\mathrm{CO}_{2}$ Capture by Absorption and Adsorption. Aerosol and Air Quality Research, 12(5), 745-769.

Zolotov, Y. A. (2010) The General Methodology of Analytical Environmental Control. Journal of Analytical Chemistry, 65(3), 221-222. 